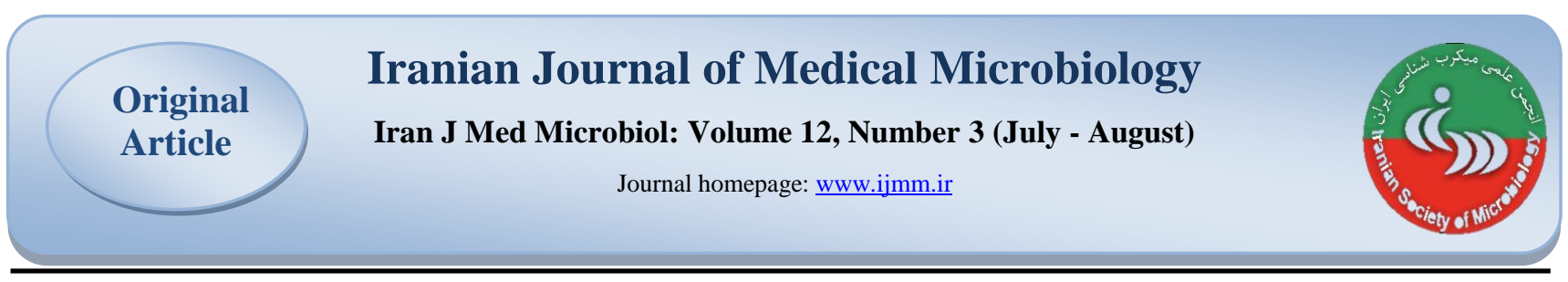

\title{
Identification and Characterization of Staphylococcus aureus Methicillin and Vancomycin Resistance from Patients in Sari and Ghaemshahr Injuries and Burn Hospitals in 2015
}

\section{Mohammad Movagharnezhad, Mohammad Reza Khataminezhad}

Department of Microbiology, Faculty of Biology, Islamic Azad University, Tonekabon, Iran

\section{Article Information}

\section{Article history:}

Received: 2016/01/28

Accepted: 2016/10/16

Available online: 2018/10/11

Article Subject:

Antibiotic Resistance

IJMM 2018; 12(3): 160-168

Corresponding author:

Mohammad Movagharnezhad

Department of Microbiology,

Faculty of Biology, Islamic

Azad University, Tonekabon,

Iran

Tel: 09112283835

Email:

mohammadmovagharnezhad @yahoo.com

Use your device to scan and read the article online

\section{Abstract}

Background and Aims: Staphylococcus aureus is the most common and important nosocomial pathogens and due to potential virulence and increasing resistance to anti-microbial medicines, they become one of the most important health problems through worldwide. So the aim of this study was identification and characterization of $S$. aureus resistant to Methicillin and Vancomycin from patients hospitalized in Razi hospital of Ghaemshahr and Shahid Zare of Sari and characteristics antibiotics susceptibility pattern in 2015.

Materials and Methods: In this cross-sectional descriptive study, 134 strains of S. aureus from hospitalized patients in infectious diseases and burns were collected randomly from the hospital laboratory and transferred to the research laboratory. The specimens were incubated in Blood Agar medium for 24 hours at $37^{\circ} \mathrm{C}$. The colonies were examined for morphology, biochemical properties, resistance to polymixin and sensitivity to Novobiocin. For isolates, antibiotic test was performed using disk diffusion method and PCR detection was performed. PCR results were approved for sequencing.

Results: 100 out of 134 samples were positive for S. aureus; 51 samples were methicillinresistant and 2 samples were resistant to all of the antibiotics and Vancomycin with vanA and vanB resistance gene.

Conclusions: Determination of new resistance factor in nosocomial infection is one of the major challenges in treating these infections. $25.37 \%$ of the samples, weren't $S$. aureus. This study showed $51 \%$ prevalence of methicillin-resistance.

Keywords: Staphylococcus aureus, Resistance, Methicillin, Vancomycin

How to cite this article:

Movagharnezhad M, khataminezhad M R. Identification and Characterization of Staphylococcus Aureus Methicillin and Vancomycin Resistance From Patients in Sari and Ghaemshahr Injuries and Burn Hospitals in 2015. Iran J Med Microbiol. 2018; 12 (3) :160168 


$$
\text { مجله ميكروبشناسى يزشكى ايران }
$$

Journal homepage: www.ijmm.ir
مقاله

بثزوهشى

\section{شناسـايى و بررسى الكوى مقاومت آنتى بيوتيكى استافيلوكوكوس اورئوس مقاوم بـ متىسيلين و وانكومايسين در بيماران بسترى در بخشهاى عفونى، سوانح و سوختكى بيمارستانهاى سارى و قائمشهر در سال توبال}

محمد موقرنزاد، محمدرضا خاتمىنزاد

كروه ميكروبيولوزى، دانشكدة علوم زيستى، دانشكاه آزاد اسلامى، تنكابن، ايران

\section{جـكيده}

زمينه و هدف:/ستافيلوكوكوس /ورئوس از مههمترين و شايعترين ياتورنهاى بيمارستانى است و بهدليل قدرت بيمارىزايى بالقوه

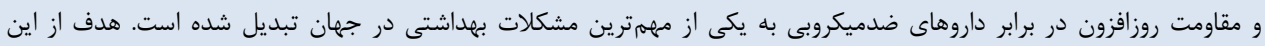

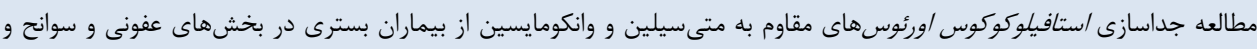

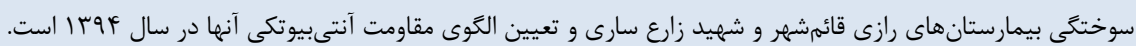

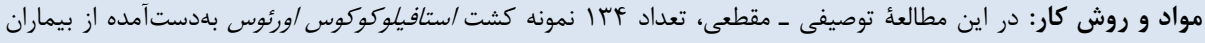

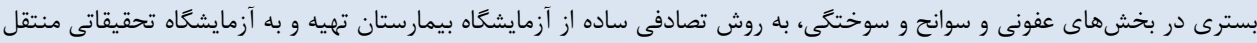

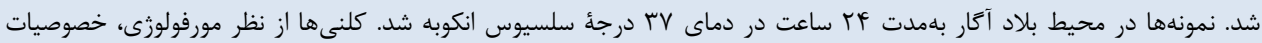

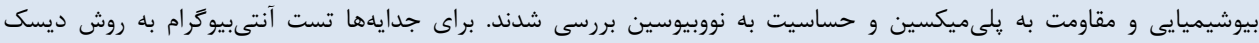

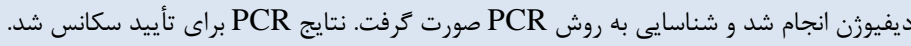

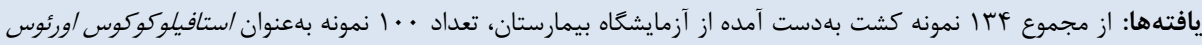

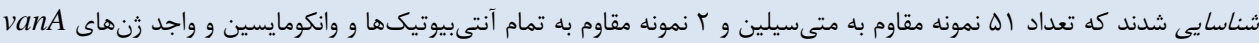

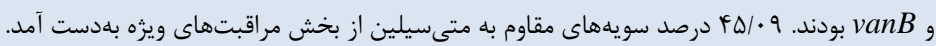

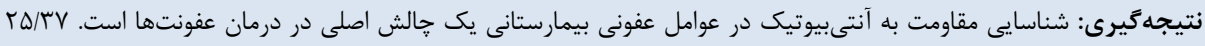

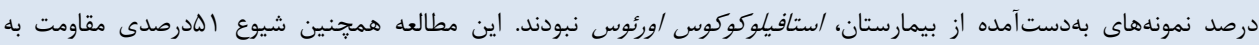

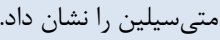
كلمات كليدى: استافيلوكوكوس /ورئوس، مقاومت، متى سيلين، وانكومايسين كبيىرايت (C: حق جاب، نشر و استفادهُ علمى از اين مقاله براى مجلُّ ميكروبشناسى بزشكى ايران محفوظ است.
اطلاعات مقاله

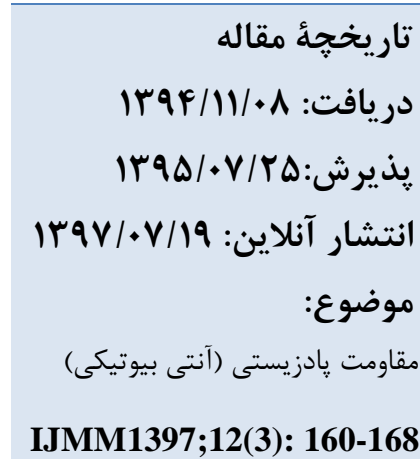

نويسندهُ مسئول: محمد موقرنزاد

كروه ميكروبيولوزى، دانشكدة علوم زيستى، دانشعاه آزاد اسلامى، تنكابن، داندكاء علوم ايران

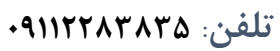

يست الكترونيك:

Mohammadmova gharnezhad@yahoo.com
عفونتهاى داخل عروقى، ينومونى، آرتريت سيتيك، اندوكارديت،

استئوميليت، عفونت جسم خارجى و سيسيس است (ه-F).

اين باكترى مىتواند بلهورت مؤثر زنهاى مقاومت بله

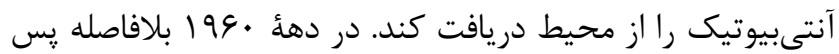
از معرفى متىسيلين، سويههاى /ستافيلوكوكوس اورئوس مقاوم به اين دارو ظاهر شدند و /ستافيلوكوكوس اورئوسهاى مقاوم به متىسيلين ( Methicillin-resistant Staphylococcus aureus:
استافيلوكوكوس اورئوس كو كسى گرم مثبت است كه در زير ميكروسكوٍ، ظاهرى شبيه به خوشأ انگور دارد (1) و كلنىهاى

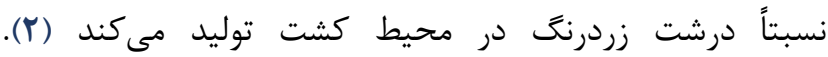
استافيلوكوكوس /ورئوس بهطور معمول از يوست و بينى افراد سالم

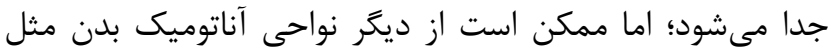
دهان و دستخاه گوارش نيز جدا شود (r). اين باكترى يكى از عوامل عمده عفونتهاى بيمارستانى، عفونت يوست و بافت نرم، 
بيمارستانهاى رازى قائمشهر و شهيد زارع سارى تهيه شد.

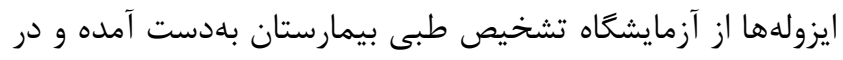

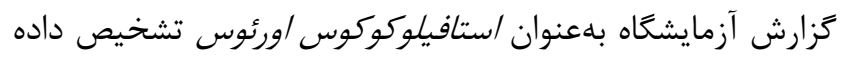

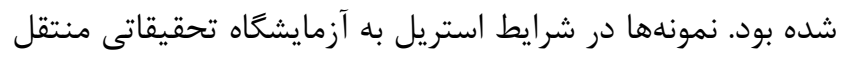

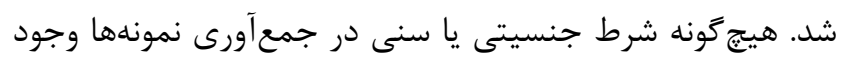

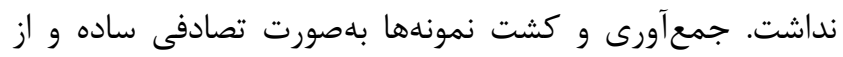

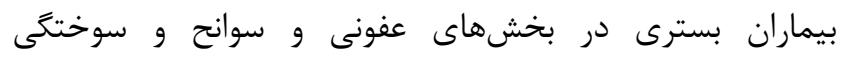

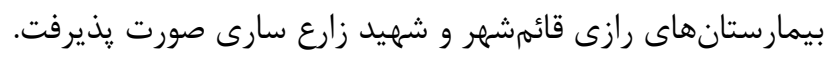

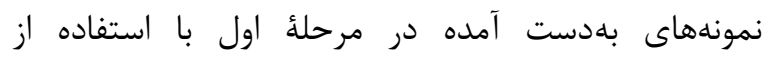

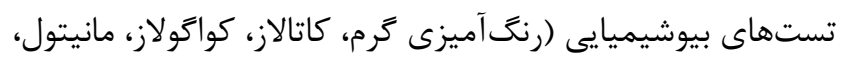

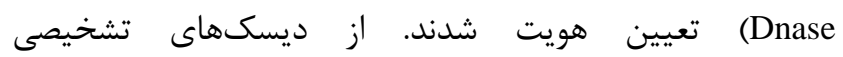

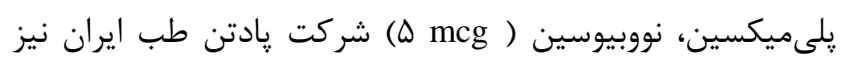

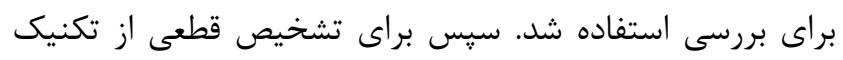
PCR

\section{DNA استخراج}

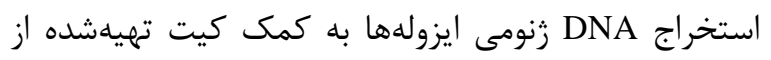

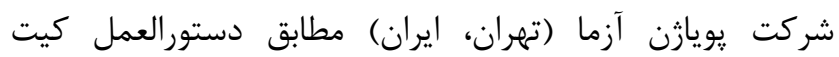
استخراج شد. DNA استخراجشده از طريق لود كردن ه ميكروليتر از DNA روى زل آكاروز 1 درصد بهصورت كمّى بررسى شد شد.

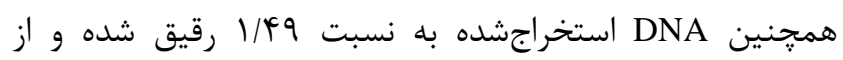

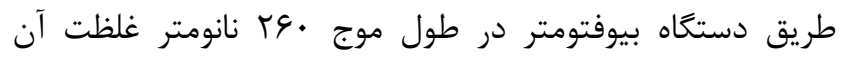

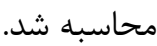

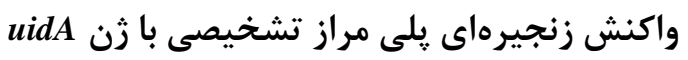

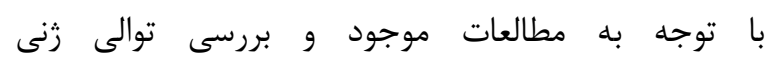

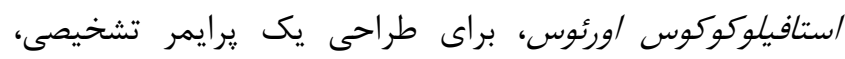

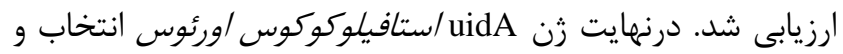

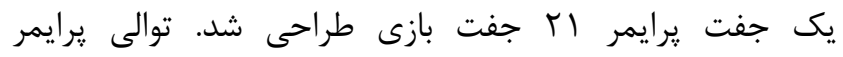

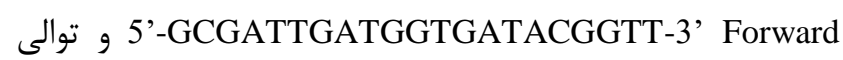
5'AGCCAACCTTGACGACTAAGC-3' Reverse برايمر

واكنش زنجيرهاى يليمر بلمنظور شناسايى دقيق نمونهها

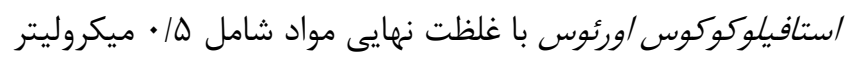
dNTP (10mM) 1 ميكروليتر (10)

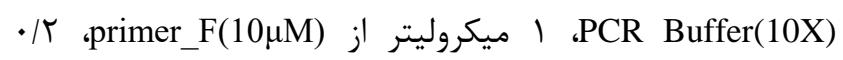

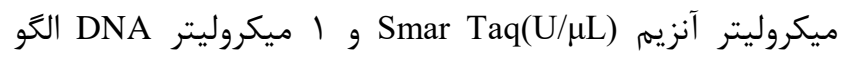
استفاده شد. حجم نهايى با افزودن V/A (100ng/ul)

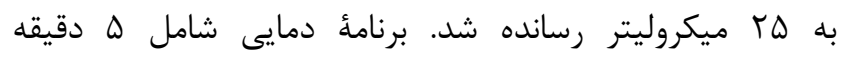

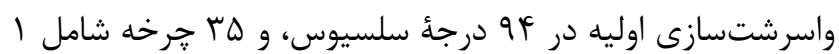

(MRSA نام گرفتند (9). عواقب عفونت با /ستافيلوكوكوس

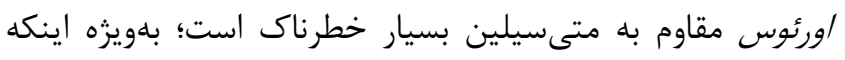

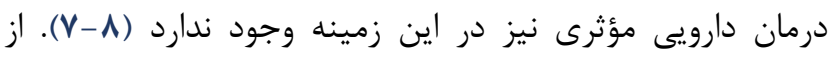

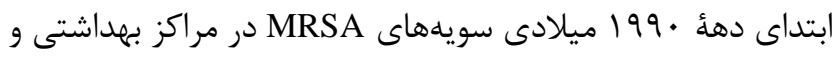

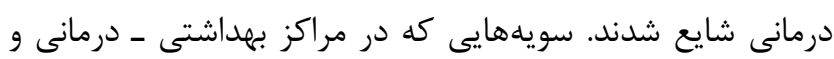

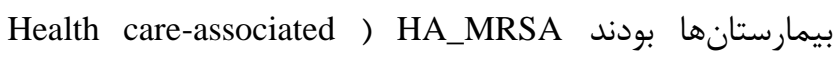
ناميده شدند؛ بهتدريج تعدادى از عفونتهاى MRSA درد

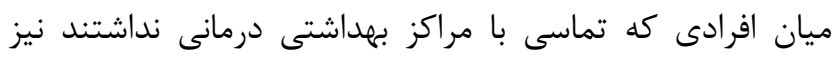

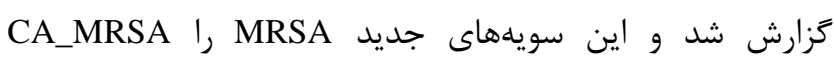
نام كذارى كردند، سويههاى (Community-associated MRSA) بهسرعت در ميان جمعيت زيادى از مردم دنيا CA_MRSA

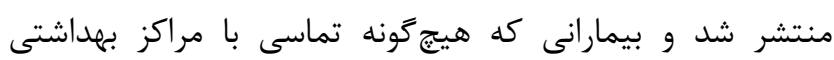

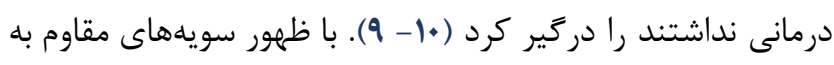

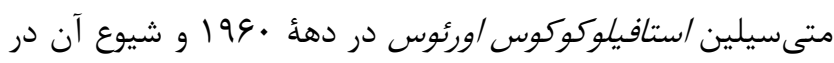

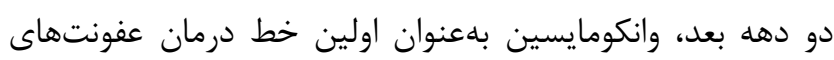

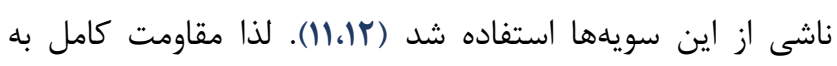

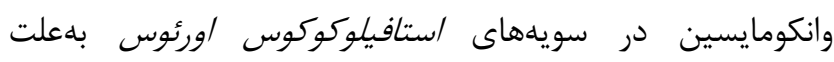

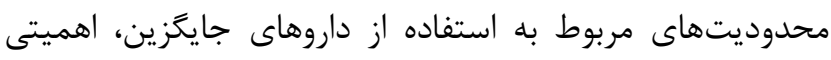

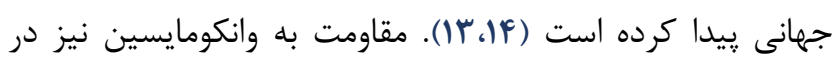
سالهاى اخير كزارش شده است.

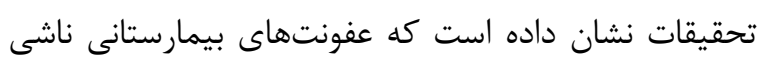

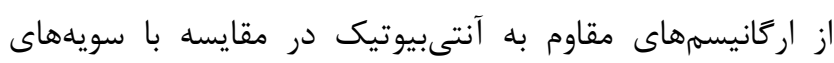

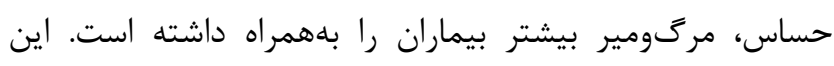

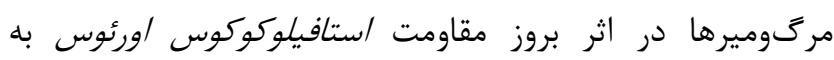

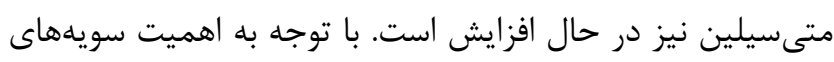

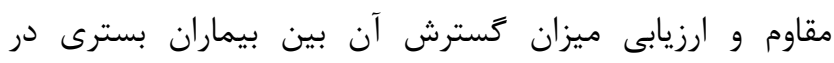

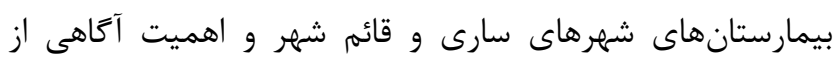

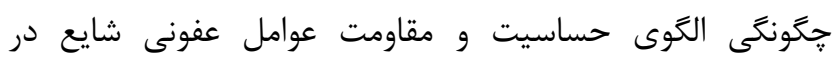

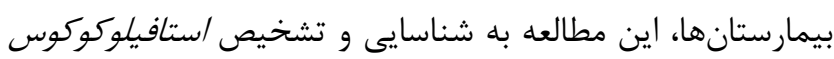

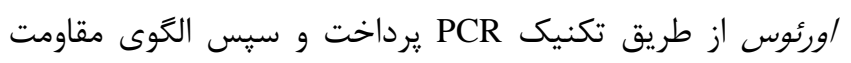

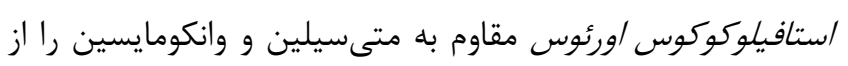

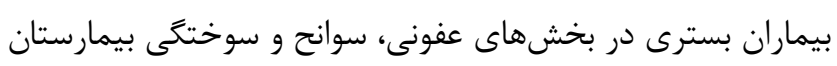

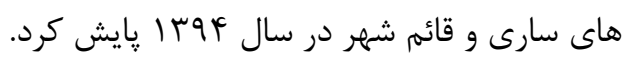

$$
\text { مواد و روشهاي ساري }
$$

\section{نمونه تيرى و بررسى خصوصيات بيوشيميايى}

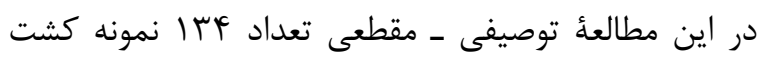

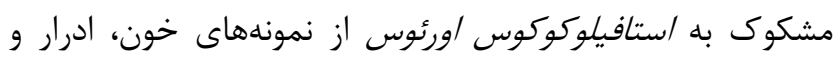

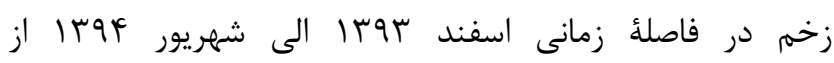


متو يريم (ه ميكروگرم)، نووبيوسين (ه ميكروگرم)، يلى ميكسين

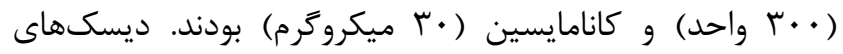
آنتىبيوتيك از شركت يادتن طب تهيه شده و كلية آزمايشها، سه

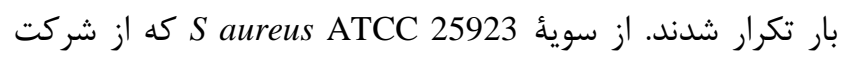
يادتن طب (تهران، ايران) تهيه شده بود، بهعنوان كنترل كيفى لته ديسكها و نمونهُ كنترل مثبت استفاده شد.

تكثير زنهاى vanA vanB و vanC زنومى با روش

PCR

براى بررسى زنوتييى مقاومت به وانكومايسين، تكثير زنهاى

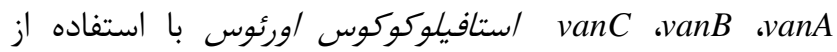
يرايمرهاى اختصاصى كه بهترتيب در زير توالى آن آمده است،

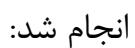

دقيقه واسرشتسازى در qF درجه سلسيوس، ·ץ ثانيه مرحله

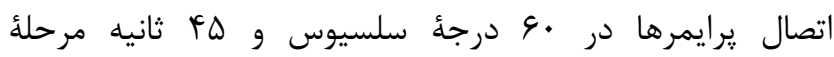
طويلسازى در VY درجهُ سلسيوس انجام شد. درنهايت مرحله طويلسازى نهايى در VT درجه سلسيوس بلهمدت ده دقيقه صورت كرفت. (- م

\section{بررسى الكوى مقاومت آنتىبيوتيكى}

ارزيابى حساسيت آنتىبيوتيكى ايزولههاى استافيلوكوكوس

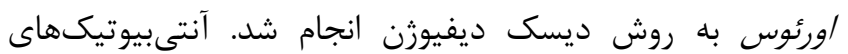

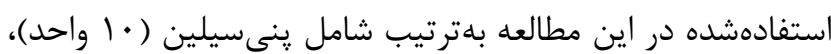

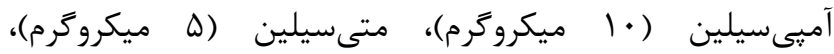

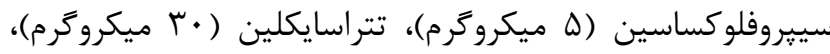

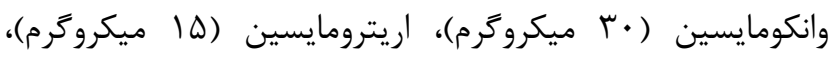

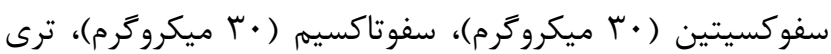

جدول ا. توالى نوكلئوتيدى يرايمرهاى استفادهشده براى رديابى مولكولى زنهاى مقاومت به وانكومايسين

\begin{tabular}{|c|c|c|}
\hline 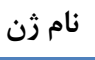 & توالى يرايمر r-ه & طول قطعه \\
\hline vanA & $\begin{array}{l}\text { ATGAATAGAATAAAAGTTGCAATAC } \\
\text { CCCСTTTAACGCTAATACGAT }\end{array}$ & r ז.ا جفت باز \\
\hline$v a n B$ & $\begin{array}{l}\text { TTGCTCAGAGGAGCATGAC } \\
\text { TAACGCAATACGATCAAGCG }\end{array}$ & جفت باز \&FV \\
\hline $\operatorname{van} C$ & $\begin{array}{c}\text { ATGGATTGGTACTGGTAT } \\
\text { TAGCGGGAGTGTCTGGTAA }\end{array}$ & ها1 جفت باز \\
\hline
\end{tabular}

جدول r. برنامهُ دمايى براى تشخيص ثنهاى مقاومت به وانكوما يسين

\begin{tabular}{ccccccc}
\hline \multirow{2}{*}{ Primers } & \multicolumn{4}{c}{ PCR conditions } \\
\cline { 2 - 7 } & $\begin{array}{c}\text { Initial } \\
\text { denaturation }\end{array}$ & Denaturation & Annealing & Extension & Final extension $\begin{array}{c}\text { Cycle } \\
\text { Number }\end{array}$ \\
vanA & $5 \mathrm{~min}$ at $94^{\circ} \mathrm{C}$ & $1 \mathrm{~min}$ at $94^{\circ} \mathrm{C}$ & $1 \mathrm{~min}$ at $52^{\circ} \mathrm{C}$ & $1 \mathrm{~min}$ at $72^{\circ} \mathrm{C}$ & $6 \mathrm{~min}$ at $72^{\circ} \mathrm{C}$ & 35 \\
vanB & $5 \mathrm{~min}$ at $94^{\circ} \mathrm{C}$ & $1 \mathrm{~min}$ at $94^{\circ} \mathrm{C}$ & $30 \mathrm{sec}$ at $50^{\circ} \mathrm{C}$ & $45 \sec$ at $72^{\circ} \mathrm{C}$ & $7 \mathrm{~min}$ at $72^{\circ} \mathrm{C}$ & 35 \\
vanC & $5 \min$ at $94^{\circ} \mathrm{C}$ & $1 \mathrm{~min}$ at $94^{\circ} \mathrm{C}$ & $62^{\circ} \mathrm{C} 30 \mathrm{sec}$ at & $30 \sec$ at $72^{\circ} \mathrm{C}$ & $5 \mathrm{~min}$ at $72^{\circ} \mathrm{C}$ & 35 \\
\hline
\end{tabular}

$$
\text { آناليز آمارى }
$$

نتايج بهدستآمده با استفاده از نرمافزار آمارى SPSS نسخئ ع) آناليز آمارى شدند. براى مقايسٔ توزيع فراوانى زنها در نمونههاى كشت از آزمون مربع كاى استفاده و در هر مورد P-value محاسبه شد. براى اين مطالعه مقدار Pكمتر از ه. از لحاظ آمارى معنى دار تلقى شد.
براى انجام PCR و تكثير اين زنها از شرايط مختلف دمايى و تركيب مسترميكس استفاده شد. براى زن هر سه زن مسترميكس

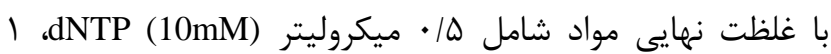

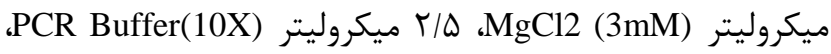

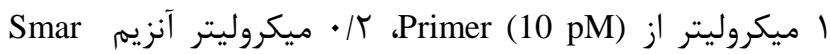

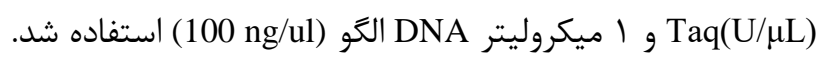
بامنظور تكثير زن vanC از غلظت درنهايت براى تأييد صحت محصولات PCR ايجادشده، اين قطعات تكثيرشده تعيين توالى شدند. 
همجنين بيشترين نمونهاى مقاومت به انواع آنتىبيوتيكها از

بخش مراقبتهاى ويزه بود (نمودار ().)

يافته ها

\section{نتايج توزيع نمونهها}

\section{نتايج تشخيص مولكولى كونهُ/ستافيلوكوكوس /ورئوس}

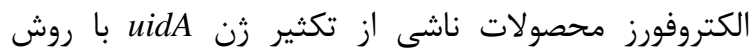

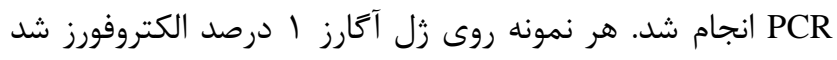

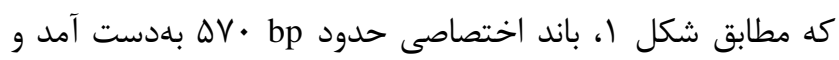

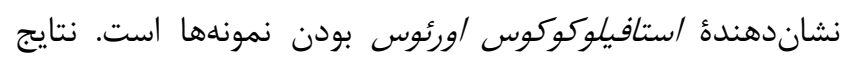

$$
\text { سكانس نيز اين موضوع را تأييد كرد. }
$$

از مجموع F ITF نمونه ارسالى به آزمايشكاه تحقيقاتى كه

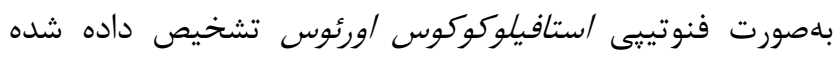

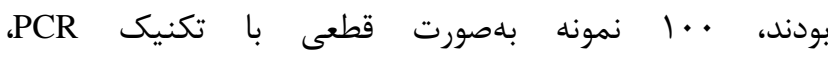

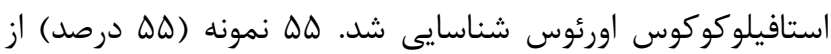

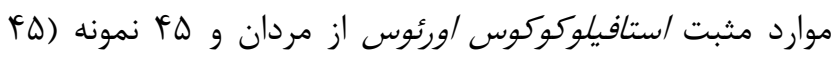

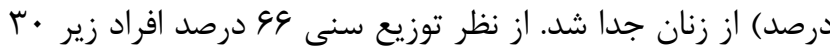

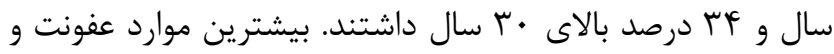

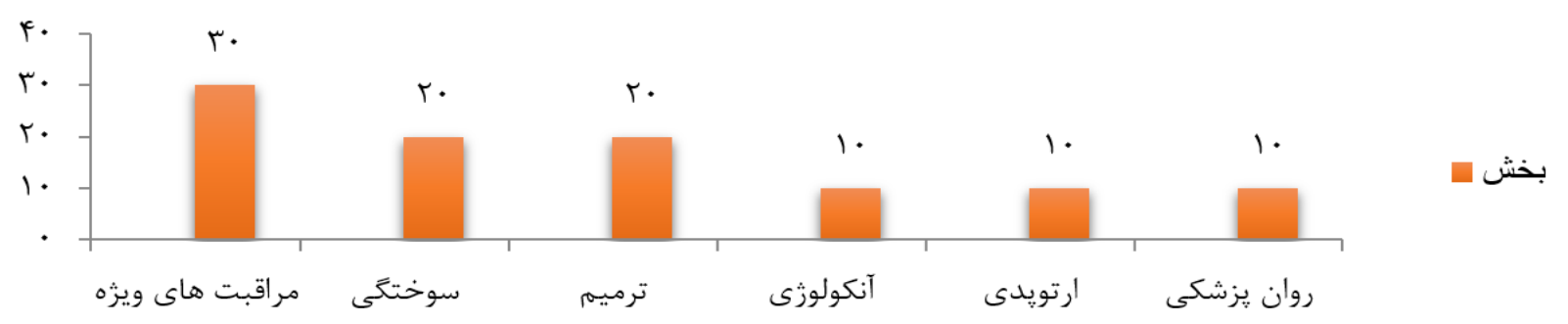

نمودار ا. نتايج كشتهاى مثبت براساس بخشى كه نمونهَيرى در آن انجام شده است (كل نمونههاى مثبت ..1 ايزوله)

به مقاومت آنتىبيوتيكى در نمودار Y مشخص شده است (نمودار . (

همجنين با توجه به اهميت سويههاى مقاوم به متىسيلين،

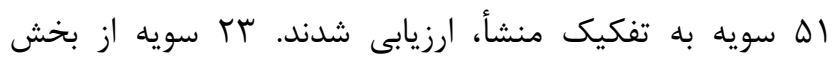

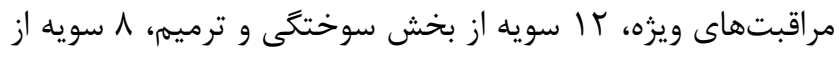

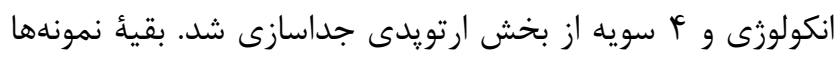

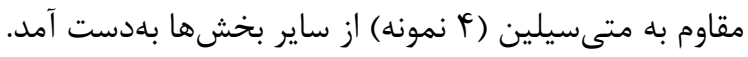

\section{نتايج رديابى مولكولى زن vanC ،vanB vvanA}

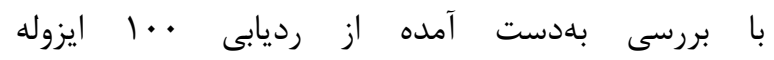

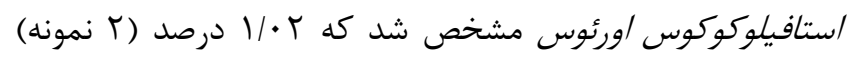

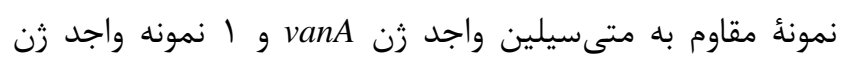

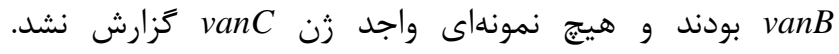
همجنين نمونهاى كه واجد زن vanA بود، vanB هم داشت. شكل

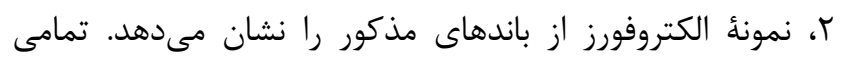

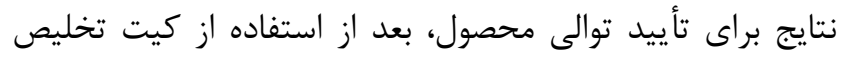

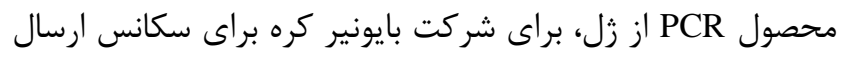

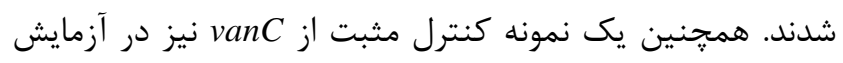

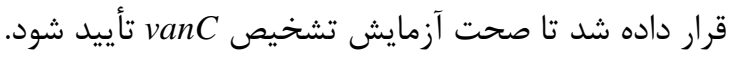

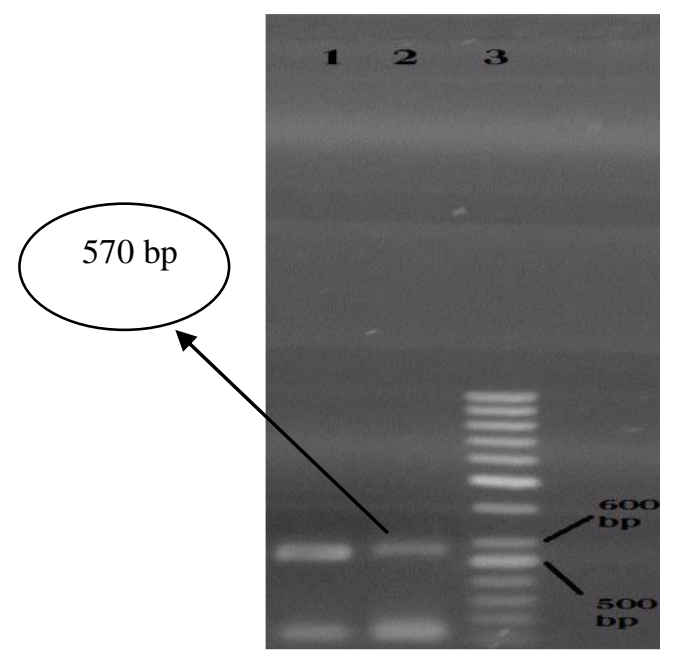

شكل ا. الكتروفورز محصول PCR زن شidA در شكل مشخص است.

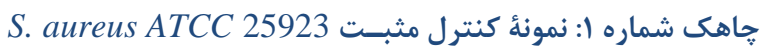
و جاهك شماره r: يك نمونة بالينى را نشان مى دهد.

\section{نتايج مقاومت آنتىبيوتيكى}

از بين ·. إويه /ستافيلوكوكوس /ورئوس تمام نمونهها به

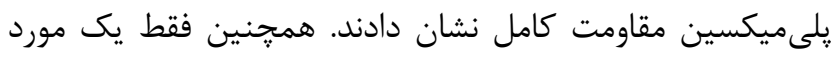

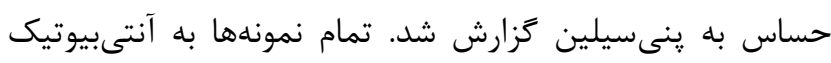

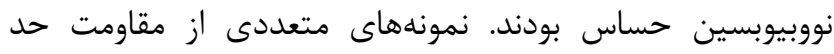

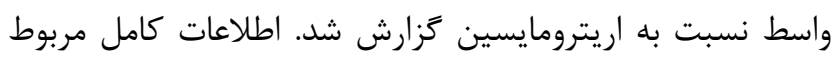




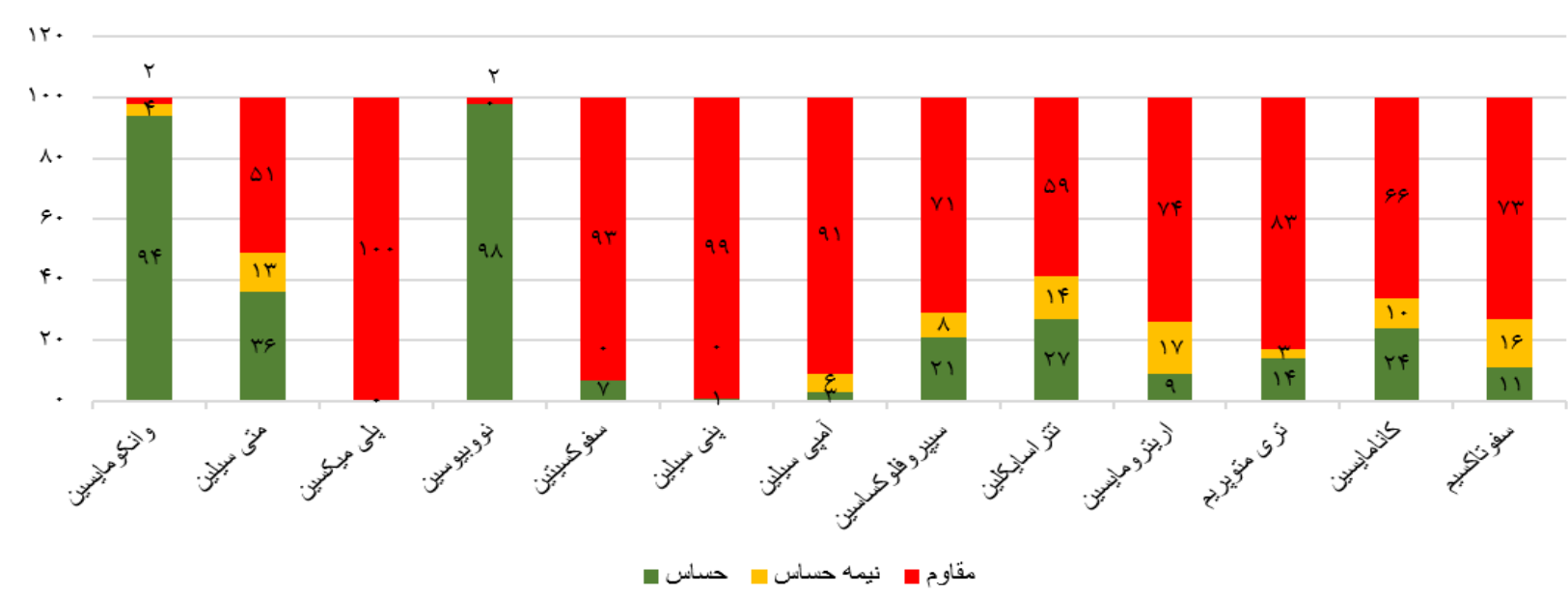

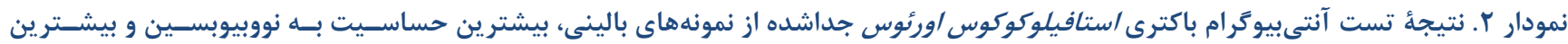

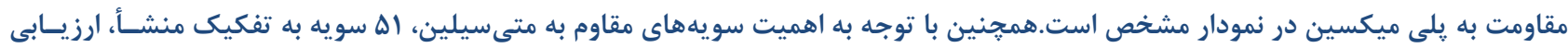

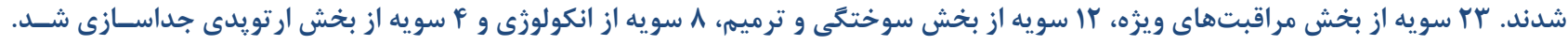

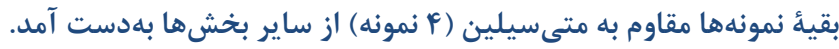

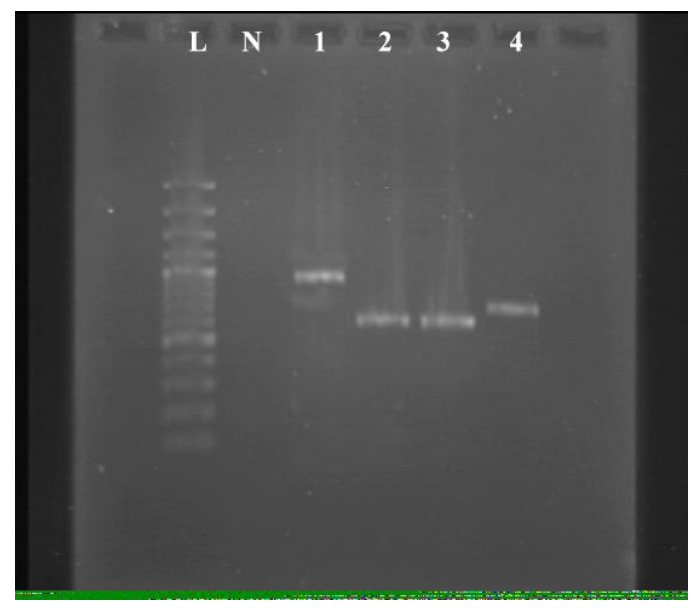

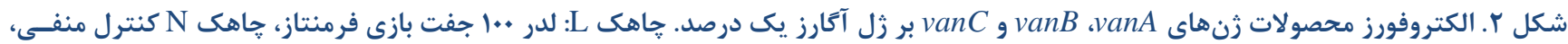

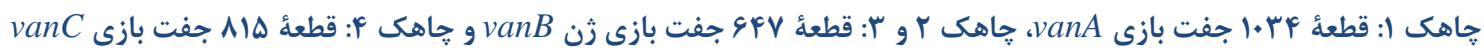

تاكنون مطالعات مختلفى دربارئ /ستافيلوكوكوس اورئوسهاى مقاوم نسبت به متىسيلين و وانكومايسين در نقاط

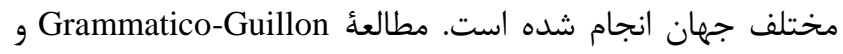

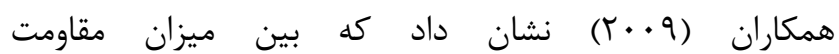

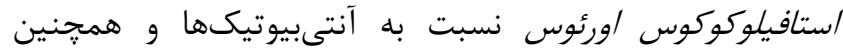

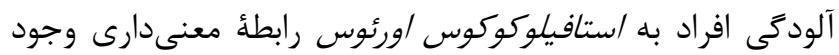

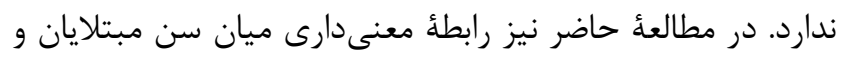

ابتلا به عفونتهاى /ستافيلوكوكوس /ورئوس بهدست نيامد (IV). Sancak

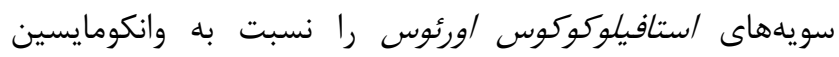

بحث و نتيجه كيرى

استافيلوكوكوس /ورئوس طى جند دهأ كذشته تبديل به يكى از شايعترين عوامل عفونتهاى بيمارستانى شده است (ها).

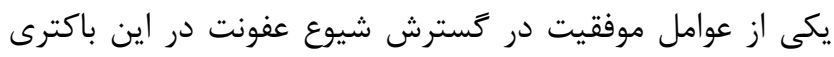

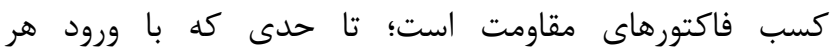
آنتىبيوتيك جديد سويههاى مقاوم باكترى بهسرعت ظهور يافته و

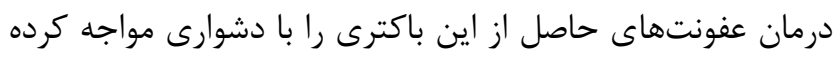

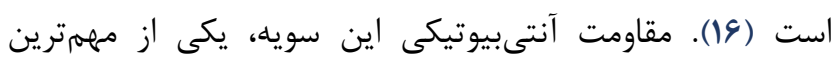
تهديدهاى ميكروبى بيمارستانى بهشمار مىرود. 
vanB و vanA

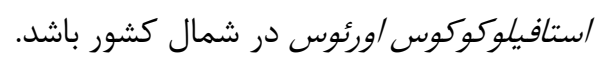
Mansouri Ghiasi

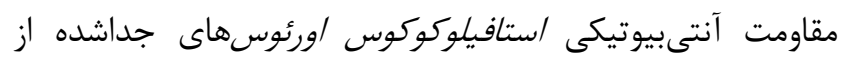

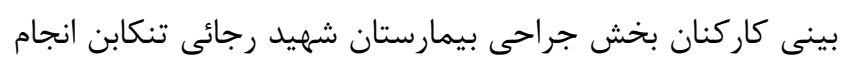

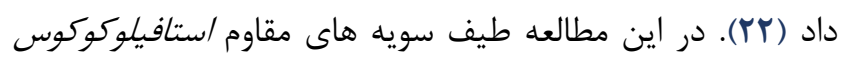

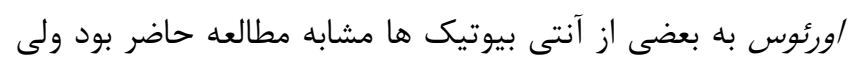

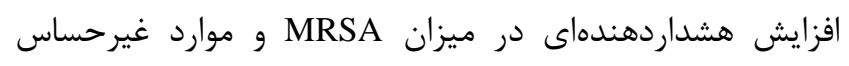

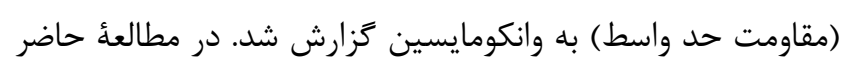

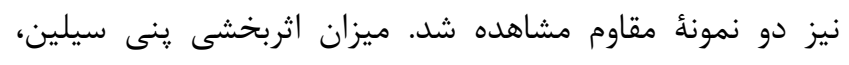

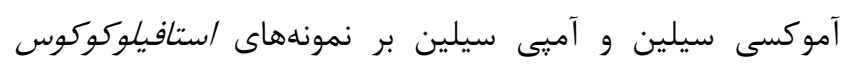

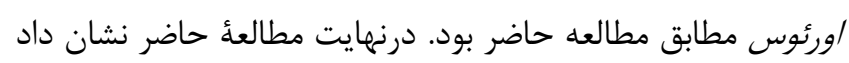

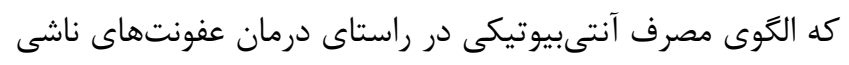

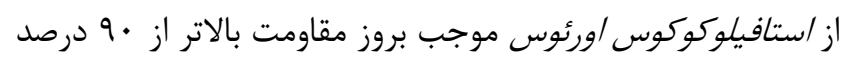

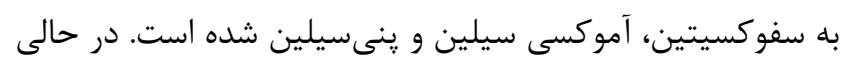

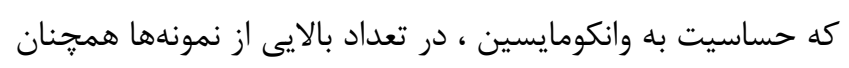

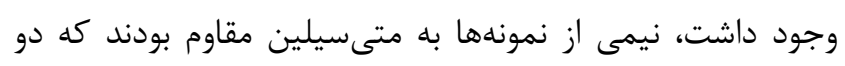

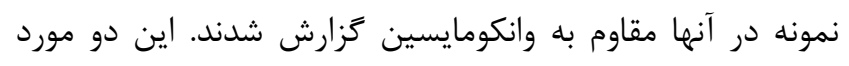

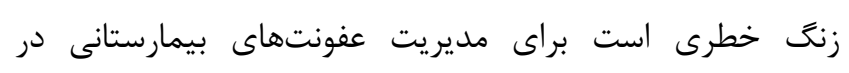

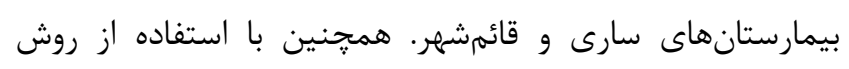
مشخص شد كه MF PCR

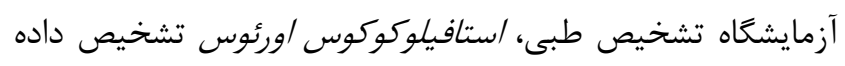

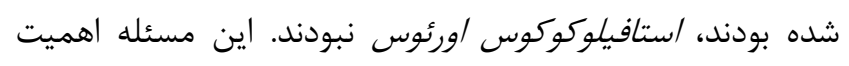

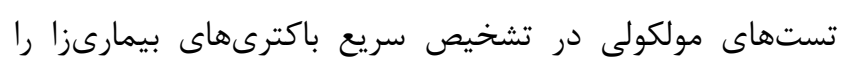

$$
\text { نشان مى دهد. }
$$$$
\text { سياسگزارى }
$$

اين مطالعه، حاصل بايان نامئ كارشناسى ارشد، دانشگاه آزاد

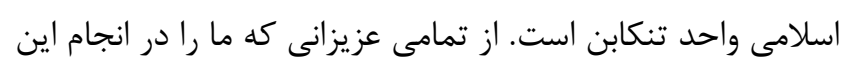
يزوهش يارى فرمودند، تشكر و قدردانى مى كنيم.

$$
\text { تعارض منافع }
$$

بين نويسندكان تعارض در منافع گزارش نشده است.
حساس گزارش كردند (1)). در يزوهش حاضر نيز r سويأ مقاوم

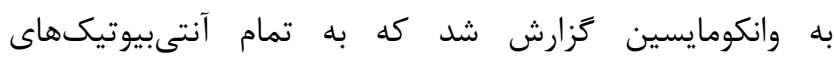
مطالعهشده مقاومت كامل نشان دادند. مقاومت آنتىبيوتيكى اين كاين

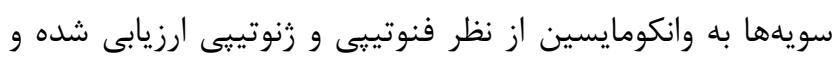

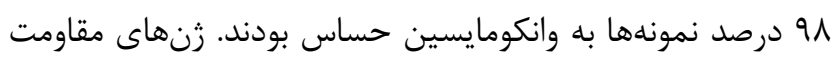
vanA

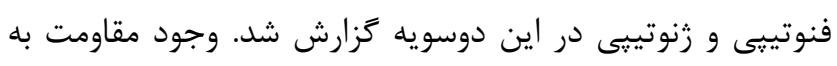

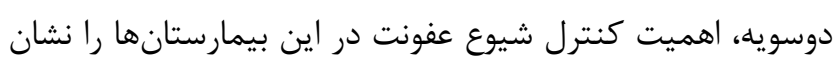

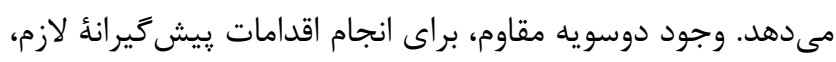
به آزمايشكاه بيمارستان اطلاعرسانى شد.

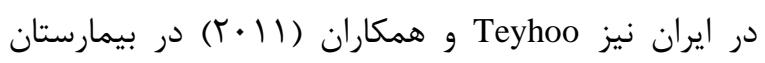

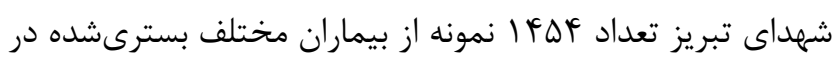

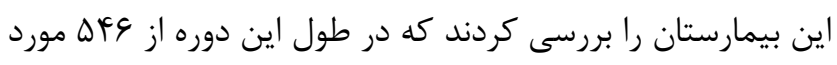

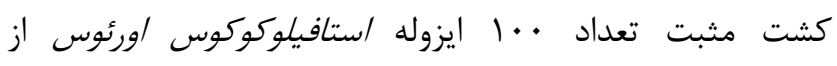

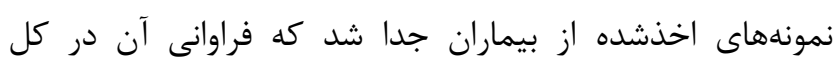

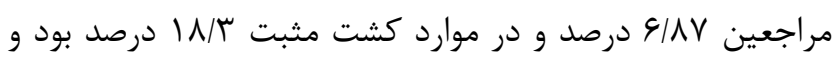

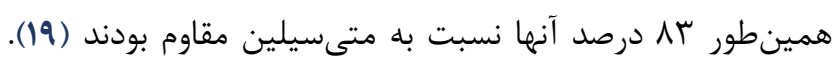

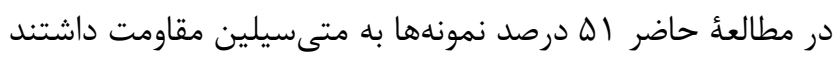

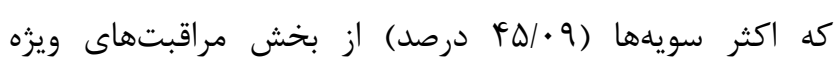
جداسازى شدند.

و Darabi

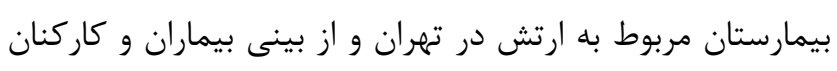

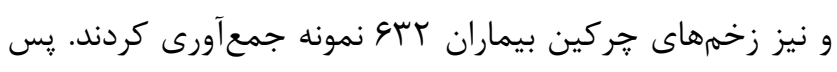

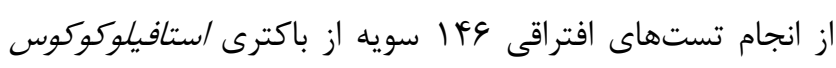

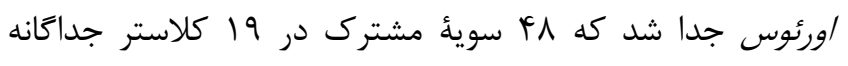

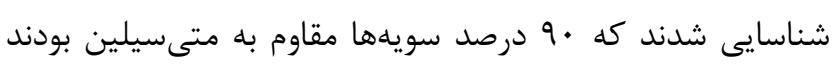

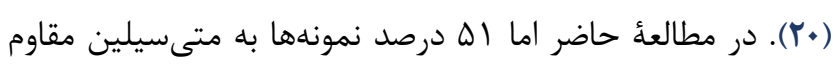

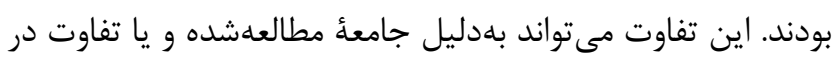
تعداد نمونه كيرى باشد. Afrough

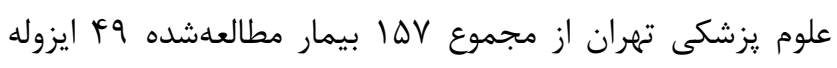

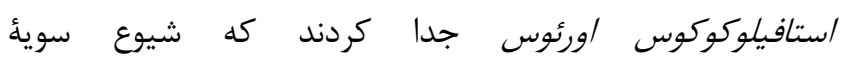

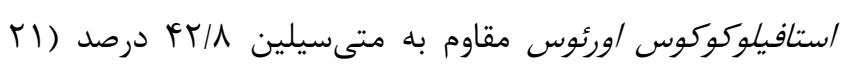

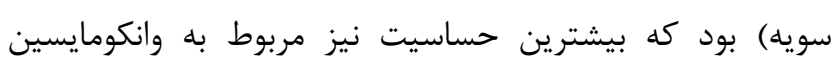

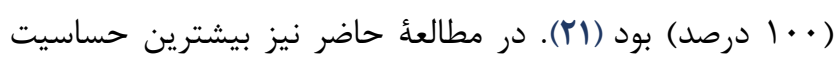

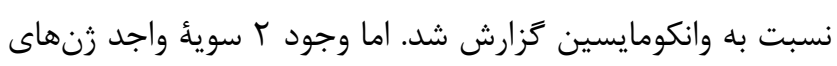




\section{References}

1. Yoshida K, Ekstedt RD. Relation of mucoid growth of Staphylococcus aureus to clumping factor reaction, morphology in serum-soft agar, and virulence. J Bacteriol 1968;96(4):902-8.

2. Owens WE, Nickerson SC. Morphologic study of Staphylococcus aureus L-form, reverting, and intermediate colonies in situ. $\mathbf{J}$ Clin Microbiol 1989;27(6):1382-6.

3. Tong SY, Davis JS, Eichenberger E, Holland TL, Fowler VG. Staphylococcus aureus infections: epidemiology, pathophysiology, clinical manifestations, and management. Clin Microbiol Rev 2015;28(3):603-61.

https://doi.org/10.1128/CMR.00134-14

PMID:26016486 PMCID:PMC4451395

4. Holland TL, Arnold C, Fowler VG. Clinical management of Staphylococcus aureus bacteremia: a review. JAMA 2014;312(13):1330-41. https://doi.org/10.1001/jama.2014.9743

PMID:25268440 PMCid:PMC4263314.

5. Vaez H, Ghazi Saeidi K, Moradi A, Tabaraei A, Khodabakhshi B, Bazouri M. Antibiotic resistance pattern of methicillin resistant Staphylococcus aureus isolated from Health-educational centers of Gorgan, Iran, 2008-2009. Iran J Med Microbiol 2010;3(4):31-6.

6. Davis JS, Sud A, O'Sullivan MV, Robinson JO, Ferguson PE, Foo H. Combination of Vancomycin and beta-Lactam Therapy for Methicillin-Resistant Staphylococcus aureus Bacteremia: A Pilot Multicenter Randomized Controlled Trial. Clin Infect Dis 2016;62(2):173-80. https://doi.org/10.1093/cid/civ808 PMID:26349552.

7. Leiva Pelaez O, Stojanov M ,Zayas Tamayo AM, Barreras Garcia G, Gonzalez Aleman M, Martinez Ceballos L. Molecular epidemiology of methicillinresistant Staphylococcus aureus from 4 Cuban hospitals. Diagn Microbiol Infect Dis 2015;81(1):1-3. https://doi.org/10.1016/j.diagmicrobio.2014.10.012 PMID:25467174

8. Luini M, Cremonesi P, Magro G , Bianchini V, Minozzi G, Castiglioni B. Methicillin-resistant Staphylococcus aureus (MRSA) is associated with low within-herd prevalence of intra-mammary infections in dairy cows: Genotyping of isolates. Vet Microbiol 2015;178(3-4):270-4.

https://doi.org/10.1016/j.vetmic.2015.05.010

PMID:26009302

9. Kahanov L, Kim YK, Eberman L, Dannelly K, Kaur H, Ramalinga A. Staphylococcus aureus and communityassociated methicillin-resistant Staphylococcus aureus (CA-MRSA) in and around therapeutic whirlpools in college athletic training rooms. J Athl Train 2015;50(4):432-7. https://doi.org/10.4085/1062-6050-49.3.96

PMID:25710853 PMCID:PMC4560002

10. Kumari VH, Babu AR, Srinivas D, Siddaiah N, Somanna S. Methicillin-Resistant Staphylococcus aureus central nervous system infections--Analysis and outcome. $\mathrm{Br} \quad \mathrm{J}$ Neurosurg 2015;29(3):413-8. https://doi.org/10.3109/02688697.2015.1006168 PMID:25688639

11. Holmes NE, Tong SY, Davis JS, van Hal SJ. Treatment of methicillin-resistant Staphylococcus aureus: vancomycin and beyond. Semin Respir Crit Care Med 2015;36(1):17-30. https://doi.org/10.1055/s0034-1397040 PMID:25643268

12. Inomata S, Yano H, Tokuda K, Kanamori H, Endo S, Ishizawa C. Microbiological and molecular epidemiological analyses of community-associated methicillin-resistant Staphylococcus aureus at a tertiary care hospital in Japan. J Infect Chemother 2015;21(10):729-36.

https://doi.org/10.1016/j.jiac.2015.07.005

PMID:26271590

13. Cazares-Dominguez V, Cruz-Cordova A, Ochoa SA, Escalona G, Arellano-Galindo J, Rodriguez-Leviz A. Vancomycin tolerant, methicillin-resistant Staphylococcus aureus reveals the effects of vancomycin on cell wall thickening. PLoS One $2015 ; 10(3)$ : 0118791-16. https://doi.org/10.1371/journal.pone.0118791 PMID:25793280 PMCID:PMC4368777

14. Soong G, Paulino F, Wachtel S, Parker D, Wickersham M, Zhang D. Methicillin-resistant Staphylococcus aureus adaptation to human keratinocytes. MBio 2015;6(2):e00289-15.

https://doi.org/10.1128/mBio.00289-15

PMID:25900653 PMCID:PMC4453558

15. Ahmad MK, Asrar A. Prevalence of methicillin resistant Staphylococcus aureus in pyogenic community and hospital acquired skin and soft tissues infections. J Pak Med Assoc 2014;64(8):892-5.

16. Kim CJ, Kim HB, Oh MD, Kim Y, Kim A, Oh SH. The burden of nosocomial staphylococcus aureus bloodstream infection in South Korea: a prospective hospital-based nationwide study. BMC Infect Dis 2014;14:590.

https://doi.org/10.1186/s12879-014-0590-4

PMID:25891200 PMCid:PMC4247623

17. Grammatico-Guillon L, Thiolet JM ,Bernillon P, Coignard B, Khoshnood B, Desenclos JC. Relationship between the prevalence of methicillin-resistant Staphylococcus aureus infection and indicators of nosocomial infection control measures: a populationbased study in French hospitals. Infect Control Hosp Epidemiol 2009;30(9):861-9.

https://doi.org/10.1086/599774

PMID:19637957 
18. Sancak B, Ercis S, Menemenlioglu D, Colakoglu S, Hascelik G. Methicillin-resistant Staphylococcus aureus heterogeneously resistant to vancomycin in a Turkish university hospital. J Antimicrob Chemother 2005 ;56(3):519-23.

https://doi.org/10.1093/jac/dki272

PMID:16046461

19. Teyhoo M, Mobin H, Mozafari N A, Moadab S R, Sedigh Bayan KH, Mones Rast SH. The Prevalence of Toxin Shock Syndrome oxin (TSST-1) Producing Clinical Isolates of Staphylococcus aureus StrainsIsolated from Shohada Hospital in Tabriz, Iran. J Med Lab 2011;5(1):38-44.
20.Darabi N, Habibollahi H, Shahbabian K. Molecular Epidemiology of Staphylococcus aureus Isolated from patients and personnel in Army hospital. Ann Mil Health Sci Res 2010;8(3):193-9.

21. Afrough P, Pourmand MR, Zeinalinia N, Yousefi M, Abdossamadi Z, Bagherzadeh Yazdchi S. Molecular Typing of Clinical and Nasal Carriage Isolates of Staphylococcus Aureus by spa Gene Patterns. J Mazandaran Univ Med Sci 2012;22(94):28-34.

22. Mansouri A, Nasrollahi A, Hashemi M, Rajabzadeh P, Jahangirizad M. Prevalence and antibiotic resistance of Staphylococcus aureus isolated from the nose of Tonekabon Shahid Rajaee Hospital Surgery Department. J Lab Sci. 2013;7(1):35-39. 